Research article

\title{
The impact of incident vertebral and non-vertebral fractures on health related quality of life in postmenopausal women Jonathan D Adachi*1, George Ioannidis ${ }^{2}$, Wojciech P Olszynski ${ }^{3}$, Jacques P Brown ${ }^{4}$, David A Hanley ${ }^{5}$, Rolf J Sebaldt ${ }^{6,7}$, Annie Petrie ${ }^{6}$, Alan Tenenhouse ${ }^{8}$, Gregory F Stephenson ${ }^{9}$, Alexandra Papaioannou ${ }^{10}$, Gordon H Guyatt ${ }^{11}$ and Charlie H Goldsmith ${ }^{11}$
}

Address: ${ }^{1}$ Department of Medicine, St. Joseph's Hospital, McMaster University, Hamilton, Ontario, Canada, ${ }^{2}$ Charlton Medical Centre, Hamilton, Ontario, Canada, ${ }^{3}$ Department of Medicine, University of Saskatchewan, Saskatoon, Saskatchewan, Canada, ${ }^{4}$ Department of Medicine, Laval University, Ste-Foy, Quebec, Canada, ${ }^{5}$ Department of Medicine, University of Calgary, Calgary, Alberta, Canada, ${ }^{6}$ Department of Medicine, McMaster University, Hamilton, Ontario, Canada, ${ }^{7}$ Centre for Evaluation of Medicines, St. Joseph's Hospital, Hamilton, Ontario, Canada, ${ }^{8}$ Department of Medicine, McGill University, Montreal, Quebec, Canada, ${ }^{9}$ Procter \& Gamble Pharmaceuticals, Toronto, Ontario, Canada, ${ }^{10}$ Department of Medicine, Hamilton Health Sciences, Hamilton, Ontario, Canada and ${ }^{11}$ Clinical Epidemiology and Biostatistics, McMaster University, Hamilton, Ontario, Canada

E-mail: Jonathan D Adachi* - jd.adachi@sympatico.ca; George Ioannidis - g.ioannidis@sympatico.ca; Wojciech P Olszynski - olszynski@webster.sk.ca; Jacques P Brown - Jacques.Brown@crchul.ulaval.ca; David A Hanley - dahanley@ucalgary.ca; Rolf J Sebaldt - sebaldt@mcmaster.ca; Annie Petrie - petriea@mcmaster.ca; Alan Tenenhouse - mcat@musica.mcgill.ca;

Gregory F Stephenson - stephenson.gf@pg.com; Alexandra Papaioannou - PAPAIOANNOU@HHSC.CA;

Gordon H Guyatt - guyatt@mcmaster.ca; Charlie H Goldsmith - goldsmit@fhs.csu.McMaster.CA

${ }^{*}$ Corresponding author

Published: 22 April 2002

Received: 22 November 2001

BMC Musculoskeletal Disorders 2002, 3:1 I

Accepted: 22 April 2002

This article is available from: http://www.biomedcentral.com/I47/-2474/3/I I

(C) 2002 Adachi et al; licensee BioMed Central Ltd. Verbatim copying and redistribution of this article are permitted in any medium for any purpose, provided this notice is preserved along with the article's original URL.

\begin{abstract}
Background: Little empirical research has examined the multiple consequences of osteoporosis on quality of life.

Methods: Health related quality of life (HRQL) was examined in relationship to incident fractures in 2009 postmenopausal women 50 years and older who were seen in consultation at our tertiary care, university teaching hospital-affiliated office and who were registered in the Canadian Database of Osteoporosis and Osteopenia (CANDOO) patients. Patients were divided into three study groups according to incident fracture status: vertebral fractures, non-vertebral fractures and no fractures. Baseline assessments of anthropometric data, medical history, therapeutic drug use, and prevalent fracture status were obtained from all participants. The disease-targeted mini-Osteoporosis Quality of Life Questionnaire (miniOQLQ) was used to measure HRQL.

Results: Multiple regression analyses revealed that subjects who had experienced an incident vertebral fracture had lower HRQL difference scores as compared with non-fractured participants in total score ($0.86 ; 95 \%$ confidence intervals $(\mathrm{Cl}):-1.30,-0.43)$ and the symptoms $(-0.76 ; 95 \% \mathrm{Cl}:-1.23,-0.30)$, physical functioning (-I.12; 95\% Cl: $-1.57,-0.67)$, emotional functioning $(-1.06 ; 95 \% \mathrm{Cl}:-1.44,-0.68)$, activities of daily living $(-1.47 ; 95 \% \mathrm{Cl}:-1.97,-0.96)$, and leisure $(-0.92 ; 95 \% \mathrm{Cl}:-1.37,-0.47)$ domains of the miniOQLQ. Patients who experienced an incident non-vertebral fracture had lower HRQL difference scores as compared with non-fractured participants in total score $(-0.47 ; 95 \% \mathrm{Cl}:-0.70,-0.25)$, and the symptoms $(-0.25 ; 95 \% \mathrm{Cl}:-0.49,-0.01)$, physical functioning $(-0.39 ; 95 \% \mathrm{Cl}:-0.65,-0.14)$, emotional functioning $(-0.97$; $95 \% \mathrm{Cl}:-1.20,-0.75)$ and the activities of daily living $(-0.47 ; 95 \% \mathrm{Cl}:-0.73,-0.2 \mathrm{I})$ domains.
\end{abstract}

Conclusion: Quality of life decreased in patients who sustained incident vertebral and non-vertebral fractures. 


\section{Background}

Osteoporosis, a skeletal disease characterized by low bone mass and an increased risk of bone fragility fractures, is a major health concern affecting a growing number of individuals worldwide $[1,2]$. Nearly $40 \%$ of Caucasian women age 50 years and older will experience at least one fracture of the spine, hip, or wrist during their lives [3]. These fractures have physical, psychological and social consequences that can profoundly affect health related quality of life (HRQL). Patients with fractures may be unable to work, are limited in their social and recreational activities, and are emotionally distressed [4-8]. As such, women with fractures require extensive medical, and psychological care and assistance with activities of daily living.

Quality of life measures have gained increasing attention as clinically relevant patient centered endpoints. Several instruments, both generic and disease targeted, have been created to examine health status [9-14]. However, most instruments that evaluate quality of life have been primarily developed for experimental trials. As a consequence, these quality of life instruments are not easily incorporated into the real world of clinical practice since their length and the long time needed to complete them limit their use $[15,16]$. To enhance the usefulness of HRQL instruments in clinical practice, shorter questionnaires must be developed. Our study is the first to measure the influence of incident fractures on HRQL with a disease-targeted instrument that was specifically created for clinical use.

\section{Methods}

\section{Study Design}

Data were obtained from the Canadian Database of Osteoporosis and Osteopenia (CANDOO) patients. CANDOO consists of 8065 patients and involves 8 sites across Canada (Calgary, $\mathrm{n}=20$; Saskatoon, $\mathrm{n}=357$; Winnipeg; $\mathrm{n}$ = 4; Hamilton (2 sites), $\mathrm{n}=6033$; Montreal (2 sites), $\mathrm{n}=$ 1527; Quebec City, $\mathrm{n}=124$ ). This database is a prospective registry of patients designed to capture a comprehensive set of osteoporosis-related clinical data during the course of routine specialist care [17]. In particular, the CANDOO contains electronically stored data regarding basic patient demographics, fracture history, gynecological history, past use of osteoporosis-related drug treatment, drug side effects, past use of corticosteroids and other medications, dietary calcium intake, smoking habits, type and quantity of physical activities, fall history, past medical history and family history including fractures, a self administered osteoporosis HRQL instrument, basic laboratory results, and bone density measurements. One database record, with over 400 data fields per patient, is generated for each patient at each clinical visit.
For the current analysis, the database was searched for postmenopausal women 50 years of age and older who were seen at one Hamilton site and who were registered in CANDOO from 1994 to 1999. During this time period, this location was the only CANDOO site that regularly administered the osteoporosis HRQL instrument. At the Hamilton site, all patients seen in the course of routine specialist care were entered in CANDOO. On average patients were seen annually and the HRQL instrument was administered at each clinical visit. Participants were grouped according to incident fracture status. Group I: patients who experienced clinically recognized incident vertebral fractures. Group II: patients who sustained incident non-vertebral fractures. Incident fractures were registered based on the patient's response to an item ("How many new fractures have you had since your last visit?") from the CANDOO questionnaire. Incident vertebral fractures may or may not have been confirmed by x-ray. Incident non-vertebral fractures included the ankle, arm, clavicle, elbow, heel, hip, knee, leg, nose, pelvis, rib, shoulder, sacrum, and wrist. Group III: patients who did not report an incident fracture.

Patients with incident fractures were eligible for study entry if they completed at least a portion of the HRQL questionnaire prior to (pre assessment) and following their fracture (post assessment). Patients who did not report incident fractures also had to complete the HRQL questionnaire twice. The duration between pre and post HRQL measurements was matched between the three groups.

The mini-Osteoporosis Quality of Life Questionnaire (mini-OQLQ) was used to measure HRQL. The instrument is self-administered but is reviewed by the specialist or a nurse clinician during each visit. The mini-OQLQ was derived from the original 30 item Osteoporosis Quality of Life Questionnaire (OQLQ) [18] to enhance the instrument's usefulness in clinical practice. The mini-OQLQ includes the two items from the OQLQ with the highest impact in each of the five domains (symptoms, physical functioning, emotional functioning, activities of daily living, and leisure), for a total of 10 items (Additional File). Each item is associated with a seven-point scale. The total score for the instrument can vary from 10 to 70 , while the domain scores can vary from 2 to 14 . To standardized all scores, the total and the domain scores were divided by the number of items that were used to generate the values. A standardized rating of 1 represents the worst possible function (extreme difficulties, constant fear, extreme distress) and a rating of 7 represents the best possible function (no difficulties, no fear, no distress). It has been suggested, from previous work, that changes within each domain score of approximately 0.5 represents a clinically important difference in quality of life $[19,20]$. The miniOQLQ instrument has been evaluated in osteoporotic 
women with back pain due to vertebral fractures and has been found to be reliable and valid both for measuring differences in HRQL between patients with osteoporosis and changes within these patients over time [21].

\section{Statistical Analysis}

Our primary objective was to determine the effect of vertebral and non-vertebral fractures on HRQL. Multiple regression analyses were performed to explain the relationship between incident fractures and HRQL. From these analyses, we determined regression coefficient estimates (which represent differences between pre and post HRQL measurements for both fractured and non-fractured patients), as well as $95 \%$ confidence intervals (CI) of the difference scores for the mini-OQLQ. The independent variables entered in the models included group; baseline mini-OQLQ score; group by baseline miniOQLQ score interaction; number of years between pre and post administration of the mini-OQLQ; age; baseline height; baseline weight; prevalent vertebral and non-vertebral fracture status; number of prevalent vertebral and non-vertebral fractures; time spent exercising; dietary calcium intake; baseline bone mineral density of the lumbar spine and femoral neck; medications such as bisphosphonates (etidronate or alendronate), estrogen, or others (calcitonin, fluoride or raloxifene); and co-morbidities (including heart attack; stroke; breast, ovarian, cervical, uterine and colon cancer, and multiple myeloma; diabetes, epilepsy, arthritis, and thyroid disease). Regression models were selected based on Mallows C(P) statistic. Statistical significance was defined as $\mathrm{p}<0.05$. All analyses were preformed on a Dell personal computer using a SAS/ STAT (version 7.0; SAS Institute Inc., Cary, NC, USA) software package.

\section{Results}

Of the 5450 patients entered in CANDOO from the Hamilton site, a total of 2009 postmenopausal women met the inclusion criteria of the study. The majority of patients were excluded because they were seen prior to 1994 ( $\mathrm{n}=$ 1016), did not complete the mini-OQLQ twice ( $\mathrm{n}=$ $2042)$, or were less than 50 years of age $(n=240)$. Among the women examined, 47 sustained incident vertebral and 149 developed incident non-vertebral fractures. The remaining 1813 women did not experience an incident fracture during the course of the study. The mean (standard deviation) time between baseline and follow-up administration of the mini-OQLQ for groups I, II and III was 1.2 (0.5), $1.2(0.4)$, and $1.2(0.4)$ years, respectively. The mean (standard deviation) change in height between baseline and follow-up assessment was -1.4 (1.9), -0.3 (1.2), and $-0.2(1.4) \mathrm{cm}$, for groups I, II and III respectively. Table 1 presents patient characteristics for all three groups.

\section{Incident Fractures and HRQL} Vertebral Fractures

Since changes in HRQL were similar in patients with $x$-ray confirmed vertebral fractures versus those with only reported vertebral fractures ( $20 \mathrm{vs}$. 27 patients) based on the CANDOO questionnaire (not confirmed by x-ray), all incident vertebral fracture patients were grouped together. Unadjusted HRQL standardized and difference scores were lower in patients in group I as compared with those in group III (Table 2 \& 3 ). The difference scores between groups remained statistically significant after the analysis was adjusted for the other confounding variables for the total and all five domains of the mini-OQLQ (Table 3).

\section{Non-Vertebral Fractures}

Unadjusted HRQL standardized and difference scores were lower in patients in group II as compared with those in group III (Table $2 \& 3$ ) in most domains of the miniOQLQ. After controlling for confounding variables, differences persisted in the total score, and the symptoms, physical functioning, emotional functioning and the activities of daily living domains (Table 3).

\section{Other Patient factors and HRQL}

HRQL was negatively associated with increased age, arthritis, and diabetes; whereas HRQL was positively associated with bisphosphonate use and the amount of time spent exercising. However, while these patient factors were associated with HRQL, the magnitude of the effects across the domains of the mini-OQLQ were variable and may or may not be clinically relevant (data not shown).

\section{Discussion}

The assessment of quality of life is needed to properly quantify disease burden. While clinicians and investigators may utilize a variety of questionnaires to assess their patients' HRQL, their length and the time they take to complete may restrict their clinical usefulness. Short questionnaires minimize a patient's time and effort, and thus increase a patient's willingness to complete the questionnaire. The Osteoporosis Quality of Life Study Group developed the mini-OQLQ to facilitate questionnaire administration in clinical settings. The benefit of the mini-OQLQ is that it is efficient, it is self administered, and requires 2-3 minutes to complete. Data collected from the mini-OQLQ, provide a unique opportunity to determine the effect of incident fractures on HRQL in patients seen in ordinary clinical practice.

The physical, emotional and psychological disabilities, and increased pain resulting from vertebral and non-vertebral fractures are outcomes of osteoporosis that can adversely influence HRQL. After adjusting for confounding factors, our results show substantial impairment of quality of life in patients with incident vertebral fractures as 
Table I: Patient Characteristicsa

Incident VF Group (I) Incident Non-VF Group (II) No Incident Fracture Group (III)

\begin{tabular}{|c|c|c|c|}
\hline Number of patients & 47 & 149 & 1813 \\
\hline Age-mean (SD) & $72.5(8.6)$ & $68.5(9.6)$ & $65.3(8.8)$ \\
\hline Weight-kg & $62.2(12.3)$ & $64.9(12.6)$ & $64.8(12.8)$ \\
\hline Height $-\mathrm{cm}$ & $154.4(6.7)$ & $156.9(6.6)$ & $157.4(8.3)$ \\
\hline Dietary Ca-g/d & $0.8(0.4)$ & $0.6(0.3)$ & $0.6(0.3)$ \\
\hline Exercise-hours/week & $1.8(2.6)$ & $2.8(3.4)$ & $2.9(3.5)$ \\
\hline \multicolumn{4}{|l|}{ Race-\# (\%) } \\
\hline Caucasian & $10(21.3)$ & $29(19.5)$ & $473(26.1)$ \\
\hline Other ${ }^{b}$ & $I(2.1)$ & $0(0)$ & $26(1.4)$ \\
\hline Unknown & $36(76.6)$ & $120(80.5)$ & $1314(72.5)$ \\
\hline \multicolumn{4}{|l|}{ BMD-mean (SD) } \\
\hline $\mathrm{LS}-\mathrm{g} / \mathrm{cm}^{2}$ & $0.876(0.131)$ & $0.941(0.169)$ & $0.954(0.148)$ \\
\hline $\mathrm{FN}-\mathrm{g} / \mathrm{cm}^{2}$ & $0.687(0.101)$ & $0.715(0.120)$ & $0.734(0.109)$ \\
\hline \multicolumn{4}{|l|}{ Prevalent fractures - \# (\%) } \\
\hline VF & $24(5 \mathrm{I} .1)$ & $38(25.5)$ & $326(18.0)$ \\
\hline Non-VF & $33(70.2)$ & $98(66.8)$ & $828(45.7)$ \\
\hline Multiple VF $(>1)$ & $16(34.0)$ & $17(11.4)$ & $194(10.7)$ \\
\hline Multiple Non-VF (>I) & $22(46.8)$ & $59(39.6)$ & $467(25.8)$ \\
\hline \multicolumn{4}{|c|}{ Concomitant diseases-\# (\%) } \\
\hline Heart attack & $7(14.9)$ & $25(16.8)$ & $262(14.5)$ \\
\hline Stroke & $3(6.4)$ & $3(2.0)$ & $58(3.2)$ \\
\hline Cancerc & $5(10.6)$ & $15(10.0)$ & $162(8.9)$ \\
\hline Diabetes & $2(4.3)$ & $6(4.0)$ & $58(3.2)$ \\
\hline Epilepsy & $2(4.3)$ & $2(1.3)$ & $17(0.9)$ \\
\hline Arthritis & $25(53.2)$ & $78(52.4)$ & $1037(57.2)$ \\
\hline Thyroid disease $^{\mathrm{d}}$ & $13(27.7)$ & $36(24.2)$ & $345(19.0)$ \\
\hline \multicolumn{4}{|l|}{ Medications-\# (\%) } \\
\hline Bisphosphonates ${ }^{\mathrm{e}}$ & $40(85.1)$ & $109(73.2)$ & $1252(69.1)$ \\
\hline Estrogen & $16(34.0)$ & $50(33.6)$ & $767(42.3)$ \\
\hline Other medications $\mathrm{s}^{f}$ & $4(8.5)$ & $3(2.0)$ & $42(2.3)$ \\
\hline
\end{tabular}

a $\mathrm{VF}=$ vertebral fracture; $\mathrm{Ca}=$ calcium; $\mathrm{SD}=$ standard deviation; $\mathrm{BMD}=$ bone mineral density; $\mathrm{LS}=$ lumbar spine; $\mathrm{FN}=$ femoral neck; $\#=$ number of patients; $\%=$ percent of patients within each group. ${ }^{b}$ others may have included one of the following Asian, Black, Aboriginal North American, Oriental, and Middle Eastern/North African White cincludes breast, ovarian, uterine or cervical, colon cancer; and multiple myeloma. ${ }^{d}$ includes hyper, hypo, nodular and other thyroid diseases. ${ }^{e}$ includes alendronate or etidronate. ${ }^{f}$ includes fluoride, calcitonin or raloxifene.

Table 2: Unadjusted Standardized Scores of the mini-OQLQ for Patients With and Without Incident Fractures ${ }^{\text {. }}$

\begin{tabular}{|c|c|c|c|c|c|c|c|c|c|}
\hline \multirow{2}{*}{$\begin{array}{l}\text { Mini-OQLQ } \\
\text { Domains }\end{array}$} & \multicolumn{3}{|c|}{ Vertebral Fracture Group (I) } & \multicolumn{3}{|c|}{ Non-Vertebral Fracture Group (II) } & \multicolumn{3}{|c|}{ No Fracture Group (III) } \\
\hline & Baseline & Follow-up & $\mathrm{n}$ & Baseline & Follow-up & $\mathrm{n}$ & Baseline & Follow-up & $\mathrm{n}$ \\
\hline Total Score & $4.27(1.83)$ & $3.54(\mathrm{I} .79)$ & 14 & $4.99(1.37)$ & $4.64(1.35)$ & 52 & $5.46(1.43)$ & $5.49(1.36)$ & 685 \\
\hline Symptoms & $3.98(1.76)$ & $3.26(1.65)$ & 44 & $4.82(1.62)$ & $4.64(\mathrm{I} .5 \mathrm{I})$ & 136 & $5.08(1.61)$ & $5.07(1.62)$ & 1711 \\
\hline Physical Functioning & $3.99(2.11)$ & $3.26(1.90)$ & 34 & $5.14(1.68)$ & $4.83(1.72)$ & 102 & $5.26(1.77)$ & $5.31(1.75)$ & 1192 \\
\hline $\begin{array}{l}\text { Emotional Function- } \\
\text { ing }\end{array}$ & $4.16(2.13)$ & $3.72(2.27)$ & 45 & $5.41(1.69)$ & $4.54(1.85)$ & 139 & $5.65(1.55)$ & $5.67(1.49)$ & 1711 \\
\hline $\begin{array}{l}\text { Activities of Daily } \\
\text { Living }\end{array}$ & $4.25(2.12)$ & $3.18(1.91)$ & 30 & $5.24(1.80)$ & $4.89(1.84)$ & 105 & $5.34(1.81)$ & $5.40(1.75)$ & 1260 \\
\hline Leisure & $5.10(2.07)$ & $4.31(2.20)$ & 26 & $5.42(1.84)$ & 5.51 (I.78) & 75 & $6.01(1.54)$ & $6.02(I .5 I)$ & 1012 \\
\hline
\end{tabular}

a Only patients with both pre and post measurements were evaluated. Entries are means (standard deviation). $\mathrm{n}=$ sample size. 
Table 3: Unadjusted and Adjusted Regression Coefficient Estimates and 95\% Confidence Intervals (CI) that Explain the mini-OQLQ for Patients With Incident Fractures Versus Those Without Incident Fractures ${ }^{\text {. }}$.

\begin{tabular}{|c|c|c|c|c|c|c|c|c|}
\hline \multirow{2}{*}{$\begin{array}{l}\text { Mini-OQLQ } \\
\text { Domains }\end{array}$} & \multicolumn{4}{|c|}{ Vertebral Fracture Group (I) } & \multicolumn{4}{|c|}{ Non-Vertebral Fracture Group (II) } \\
\hline & $\begin{array}{l}\text { Estimates } \\
\text { Unadjusted } \mathrm{Cl}\end{array}$ & (n) & $\begin{array}{l}\text { Adjusted } \\
\text { Estimates } \mathrm{Cl}\end{array}$ & (n) & $\begin{array}{l}\text { Unadjusted } \\
\text { Estimates Cl }\end{array}$ & (n) & $\begin{array}{l}\text { Adjusted } \\
\text { Estimates } \mathrm{Cl}\end{array}$ & (n) \\
\hline \multirow[t]{2}{*}{ Total Score } & -0.77 & $(699)$ & -0.86 & $(673)$ & -0.38 & $(737)$ & -0.47 & $(7 I I)$ \\
\hline & $-1.22,-0.31$ & & $-1.30,-0.43$ & & $-0.62,-0.13$ & & $-0.70,-0.25$ & \\
\hline \multirow[t]{2}{*}{ Symptoms } & -0.70 & $(1755)$ & -0.76 & $(1214)$ & -0.17 & $(1847)$ & -0.25 & $(1295)$ \\
\hline & $-1.12,-0.29$ & & $-1.23,-0.30$ & & $-0.4 I, 0.07 c$ & & $-0.49,-0.01$ & \\
\hline \multirow[t]{2}{*}{ Physical Functioning } & -0.76 & $(1226)$ & -1.12 & $(1113)$ & -0.35 & $(1294)$ & -0.39 & $(1 \mid 8 I)$ \\
\hline & $-1.20,-0.32$ & & $-1.57,-0.67$ & & $-0.62,-0.09$ & & $-0.65,-0.14$ & \\
\hline \multirow[t]{2}{*}{ Emotional Functioning } & -0.46 & $(1756)$ & -1.06 & $(|58|)$ & -0.90 & $(1850)$ & -0.97 & $(1669)$ \\
\hline & $-0.85,-0.07$ & & $-1.44,-0.68$ & & $-1.13,-0.66$ & & $-1.20,-0.75$ & \\
\hline \multirow[t]{2}{*}{ Activities of Daily Living } & -1.13 & $(1290)$ & -1.47 & $(1116)$ & -0.41 & $(1365)$ & -0.47 & $(1188)$ \\
\hline & $-1.63,-0.63$ & & $-1.97,-0.96$ & & $-0.69,-0.14$ & & $-0.73,-0.21$ & \\
\hline \multirow[t]{2}{*}{ Leisure } & -0.81 & $(1038)$ & -0.92 & $(991)$ & 0.08 & $(1087)$ & -0.05 & $(953)$ \\
\hline & $-1.29,-0.32$ & & $-1.37,-0.47$ & & $-0.22,0.37 c$ & & $-0.32,0.23^{c}$ & \\
\hline
\end{tabular}

\begin{abstract}
aRegression coefficient estimates and $95 \% \mathrm{Cl}$ were calculated based on differences between the incident vertebral and incident non-vertebral fracture group versus the no fracture group (reference level: no incident fracture group) between pre and post HRQL measurements. The covariates included in the multiple regression analysis were group; baseline mini-OQLQ score; group by baseline mini-OQLQ score interaction; number of years between pre and post administration of the mini-OQLQ; age; baseline height; baseline weight; change in height (post-pre); prevalent vertebral and non-vertebral fracture status; number of prevalent vertebral and non-vertebral fractures; time spent exercising (hours/week); dietary calcium intake ( $g /$ day); baseline bone mineral density of the lumbar spine and femoral neck; medications such as bisphosphonates (etidronate or alendronate), estrogen, or others (calcitonin, fluoride or raloxifene); and co-morbidities (including heart attack; stroke; breast, ovarian, cervical, uterine and colon cancer and multiple myeloma; diabetes, epilepsy, arthritis, and thyroid disease). ${ }^{b}(n)=$ sample size. ${ }^{c}$ indicates a non significant differences between groups (the non-vertebral fracture group (II) versus the no fracture group (III)).
\end{abstract}

compared with those without fractures. This was evident by the fact that HRQL was significantly lower in the total score and all domains of the mini-OQLQ.

Due to the small number of non-vertebral fractures, differences between fracture types were not examined. The mini-OQLQ was able to detect differences in HRQL between patients with incident non-vertebral and those without fractures. Statistically significant changes were seen in the total score and in the four domain scores of the mini-OQLQ. Nonetheless, the clinical relevance of these changes may be questioned. Based on these results, it is tempting to conclude that vertebral fractures have a greater impact on HRQL as compared with non-vertebral fractures. However, the mini-OQLQ was originally developed to measure the affect of vertebral fractures on quality of life and thus the instrument may be more responsive to this fracture type. As a consequence, evaluating changes in quality of life between vertebral and non-vertebral fractures is not recommended.

It should be recognized that fractures are likely to be only one of the many medical conditions that influence HRQL. Osteoporotic fractures generally affect individuals' later in life and a substantial proportion of these subjects may have clinically relevant co-morbidities. In this study, qual- ity of life was lower in patients who had either arthritis or diabetes, exercised less, or did not use bisphosphonates. While these results are clinically interesting, the findings were based on secondary analyses and therefore they should be interpreted with caution. Further research will need to be conducted to determine the clinical importance of these patient factors on HRQL.

The strengths of this cohort study include the prospective examination of both incident vertebral and non-vertebral fractures. All participants in the study were "real world" patients who were seen for osteoporosis in tertiary care settings and thus represent a homogeneous group. Our analysis adjusted for factors that may influence quality of life such as co-morbidities, medications, activity levels and baseline functional status. Furthermore, since the mini-OQLQ is a disease-targeted instrument that measures characteristics relevant to osteoporosis, it may be more sensitive in detecting differences between groups as compared with generic HRQL instruments. Nonetheless, our study is not without limitations. It is possible that other conditions such as abnormal spinal alignment, back muscle weakness, or inflexibility may have contributed to a reduced quality of life in these patients. Furthermore, not all spinal fractures were confirmed by $\mathrm{x}$-ray. X-rays were performed only in patients with back pain. There- 
fore, subclinical vertebral fractures may have developed in all groups. The presence of subclinical vertebral fracture has been documented to be associated with decreased activity [8]. As a consequence, the actual differences in HRQL scores may have been underestimated for those with documented vertebral fractures versus those without. In addition, the presence of non-vertebral fractures were based on self-reports. This method of ascertainment may lead to fracture misclassification [22].

In conclusion, this study demonstrates the detrimental impact of clinically recognized incident vertebral and non-vertebral fractures on quality of life in post-menopausal women. Despite improvements in the medical management of osteoporotic fractures, it is clear that fractured patients continue to experience decreased quality of life and that these deficits may often go unnoticed by clinicians. Thus, the challenge for the future is to develop treatment strategies to prevent and also reduce the pain associated with the fractures and to determine how patient satisfaction is impacted when quality of life issues are considered during care.

\section{Additional material}

\section{Additional File}

Appendix 1, The questionnaire includes 10 items. For each questions there are seven response options.

Click here for file

[http://www.biomedcentral.com/content/supplementary/14712474-3-11-S1.doc]

\section{References}

I. Papadimitropoulos EA, Coyte PC, Josse RG, Greenwood CR: Current and projected rates of hip fracture in Canada. Can Med Assoc J 1997, 157:1357-1363

2. Gullberg B, Johnell O, Kanis JA: World-wide projections for hip fracture. Osteoporos Int 1997, 7:407-413

3. Melton LJ III, Chrischilles A, Cooper C, Lane AW, Riggs BL: Perspective how many women have osteoporosis? J Bone Miner Res 1992, 7:1005-1010

4. Lyles KW, Gold DT, Shipp KM, et al: Association of osteoporotic vertebral compression fractures with impaired functional status. Am J Med 1993, 94:595-60|

5. Jensen GF, Bagger J: Long-term social prognosis after hip fracture. Acta Orthop Scand 1982, 53:97-101

6. Gold DT: The clinical impact of vertebral fractures: quality of life in women with osteoporosis. Bone 1996, I8(suppl 3):S185SI89

7. Cooper $\mathrm{C}$ : The crippling consequences of fractures and their impact on quality of life. Am J Med 1997, 103:I2S-19S

8. Nevitt MC, Thompson DE, Black DM, et al: Effect of alendronate on limited-activity days and bed-disability days caused by back pain in postmenopausal women with existing vertebral fractures. Arch Intern Med 2000, 160:77-85

9. Bergner M, Bobbitt RA, Carter WB, Gilson BS: The sickness impact profile: development and final revision of a health status measure. Med Care 198I, 1 9:787-805
10. Brazier JE, Harper R, Jones NM, et al: Validating the SF-36 health survey questionnaire: new outcome measure for primary care. $\mathrm{Br}$ Med J 1992, 305:160-164

II. Cook DJ, Guyatt GH, Adachi JD, et al: Quality of life issues in women with vertebral fractures due to osteoporosis. Arthritis Rheum 1993, 36:750-756

12. Helmes E, Hodsman A, Lazowski D, et al: A questionnaire to evaluate disability in osteoporotic patients with vertebral compression fractures. J Gerontol I995, 50A:91-98

13. Silverman SL, Mason J, Greenwald M: The Osteoporosis Assessment Questionnaire (OPAQ): a reliable and valid self-assessment measure of quality of life in osteoporosis. J Bone Miner Res 1993, 8:S343

14. Lips P, Cooper C, Agnusdei D, et al: Quality of life as outcome in the treatment of osteoporosis; the development of a questionnaire for quality of life by the European Foundation for Osteoporosis. Osteoporos Int 1997, 7:36-8

15. Read JL, Quinn RJ, Hoefer MA: Measuring overall health: an evaluation of three important approaches. J Chron Dis 1987, 40:7S

16. Stewart AL, Hays RD, Ware JE Jr: The MOS short form general health survey: reliability and validity in a patient population. Med Care 1988, 26:724-735

17. Sebaldt RJ, Adachi JD: Canadian database of osteoporosis and osteopenia patients (CANDOO). Canadian organization for the advancement of computers in healthcare proceedings 1996, 21:4 I-44

18. Osteoporosis quality of life study group: Measuring quality of life in women with osteoporosis. Osteoporos Int 1997, 7:478-487

19. Guyatt GH, Walter S, Norman G: Measuring change over time: assessing the usefulness of evaluative instruments. J Chron Dis 1987, 40:17I-178

20. Juniper EF, Guyatt GH, Willan A, Griffith LE: Determining a minimal important change in a disease-specific quality of life instrument. J Clin Epidemiol 1994, 47:8I-87

2I. Cook DJ, Guyatt GH, Adachi JD, et al: Development and validation of the mini-Osteoporosis Quality of Life Questionnaire in osteoporotic women with back pain due to vertebral fractures. Osteoporosis quality of life study group. Osteoporos Int 1999, 10:207-213

22. Ismail AA, O'Neill TW, Cockerill W, et al: Validity of self-report of fractures: results from a prospective study in men and women across Europe. EPOS Study Group. European Prospective Osteoporosis Study Group. Osteoporos Int 2000, I I:248-54

\section{Pre-publication history}

The pre-publication history for this paper can be accessed here:

http://www.biomedcentral.com/1471-2474/3/11/prepub

Publish with BioMed Central and every scientist can read your work free of charge

"BioMedcentral will be the most significant development for disseminating the results of biomedical research in our lifetime." Paul Nurse, Director-General, Imperial Cancer Research Fund

Publish with $\mathrm{BMC}$ and your research papers will be:

- available free of charge to the entire biomedical community

- peer reviewed and published immediately upon acceptance

- cited in PubMed and archived on PubMed Central

- yours - you keep the copyright

Submit your manuscript here BioMedcentral.com http://www.biomedcentral.com/manuscript/ 